\title{
Improvement of microstructural properties of 3Y-TZP materials by conventional and non-conventional sintering techniques
}

\author{
Amparo Borrell ${ }^{1}$, María Dolores Salvador ${ }^{2}$, Emilio Rayón $^{2}$, Felipe L. Peñaranda-Foix $^{3}$ \\ ${ }^{1}$ Centro de Investigación en Nanomateriales y Nanotecnología (CINN) (Consejo \\ Superior de Investigaciones Científicas - Universidad de Oviedo - Principado de \\ Asturias), Parque Tecnológico de Asturias, 33428 Llanera (Asturias), Spain \\ ${ }^{2}$ Instituto de Tecnología de Materiales (ITM), Universidad Politécnica de Valencia, \\ Camino de Vera, s/n, 46022 Valencia, Spain \\ ${ }^{3}$ Instituto de Aplicaciones de las Tecnologías de la Información y de las \\ Comunicaciones Avanzadas (ITACA), Universidad Politécnica de Valencia, Camino de \\ Vera, s/n, 46022 Valencia, Spain
}

*Corresponding author. Address: Centro de Investigación en Nanomateriales y Nanotecnología (CINN), Parque Tecnológico de Asturias, 33428 Llanera (Asturias), Spain. Tel.: +34985980 058; Fax: +34 985265 574. E-mail address: a.borrell@cinn.es (A. Borrell).

\begin{abstract}
$3 \mathrm{~mol} \% \mathrm{Y}_{2} \mathrm{O}_{3}$-stabilized zirconia nanopowders were fabricated using various sintering techniques; conventional sintering (CS) and non-conventional sintering such as microwave (MW) and pulsed electric current-assisted-sintering (PECS) at $1300{ }^{\circ} \mathrm{C}$ and $1400{ }^{\circ} \mathrm{C}$. A considerable difference in the densification behaviour between conventional and non-conventional sintered specimens was observed. The MW materials attain a
\end{abstract}


bulk density $99.4 \%$ theoretical density (t.d.) at $1300{ }^{\circ} \mathrm{C}$, while the CS materials attain only $92.5 \%$ t.d. and PECS $98.7 \%$ t.d. Detailed microstructural evaluation indicated that a low temperature densification leading to finer grain sizes $(135 \mathrm{~nm})$ could be achieved by PECS followed by MW with an average sintered grain size of $188 \mathrm{~nm}$ and CS 225 nm. It is believed that the high heating rate and effective particle packing are responsible for the improvements in these properties.

Keywords: A. Sintering; B. Grain size; B. Microstructure; D. $\mathrm{ZrO}_{2}$

\section{Introduction}

Recently, much effort has been focused on the synthesis and densification of ceramic nanoparticles. The reason for the interest in nanocrystalline ceramics lies in their unique properties resulting from the small grain size, and the growing significance of grain boundaries in the nanocrystalline structure [1]. Due to the excellent properties, such as low thermal conductivity, excellent biocompatibility, high fracture toughness and strength, high crack resistance and low wear rates, the Yttria-stabilized Tetragonal Zirconia Polycrystalline (Y-TZP) ceramic materials, are widely used for many applications [2].

Therefore, a variety of approaches in the field of sintering have arisen due to the widespread demand of ceramics in recent decades. Hence, understanding how the processing variables affect microstructural evolution is the key to initiating a proper sintering procedure. Various sintering methodologies based on diverse mechanisms are currently available to engineer the densification kinetics enabling the realization of above cited objectives. Applying a promising sintering procedure is, therefore, of a 
great importance for the superior performance of zirconia bodies. Conventional sintering techniques (hot pressing, sinter forging, hot isostatic pressing, etc.) and nonconventional sintering techniques (Pulsed electric current-assisted sintering and microwave) represent an alternative approach to the densification of nanoparticles. In ceramic materials, the high temperatures required to fully densify ceramic powders result in large grain sizes due to Ostwald ripening when traditional sintering techniques are used. This makes it extremely difficult to obtain dense materials with nanometric and submicrometric grain sizes [3]. To overcome the problem of grain growth, nonconventional sintering methods has been proposed in this work.

Pulsed electric current-assisted sintering simultaneously applies pulsed electrical current and pressure directly on the sample leading to densification at relatively lower temperatures and short retention times [4-6]. As both the die and sample are directly heated by the Joule effect extremely high heating rates are possible due to which nondensifying mechanisms like surface diffusion can be surpassed. This technique is widely explored for the development of nanostructured ceramics. The mechanisms responsible for high rate densification were identified as grain rotation and sliding, aided by partial melting of the particle surface or plastic deformation in materials with low yield stress $[7,8]$.

Microwave radiation for sintering of ceramic components has recently appeared as a newly focused scientific approach [9-16]. Microwave sintering has several advantages such as rapid end volumetric heating, improved production rate, enhancement in densification and grain growth prohibition of ceramics [17-19]. This technique generally uses a frequency of $2.45 \mathrm{GHz}$ resulting in relatively rapid heating rates with uniform grained microstructures and has been employed for the sintering of a wide variety of ceramics ranging from dielectric materials to transparent ceramics. 
Microwave heating of these material results from the absorption by molecular vibration (rotating electric dipole/dipole reorientation) and ionic conduction of a portion of the energy transported by an oscillating electric field [11]. A genuine "microwave effect", i.e. the acceleration of diffusion mechanisms by the oscillating electric field, was also proposed by some authors to explain the enhancement of the sintering process $[11,16,20,21]$.

The objective of the present study is therefore a comparative evaluation of the densification, microstructure development and mechanical properties in yttria-stabilized zirconia ceramics by the different sintering methodologies: conventional sintering (CS), microwave sintering (MW) and pulsed electric current-assisted sintering (PECS).

\section{Experimental procedure}

The raw material used in this study was commercial $\mathrm{ZrO}_{2}$ (3Y-TZP-B) nanopowders (Tosoh Corp., Japan) with average particle size of (50-60) nm. The MW and CS specimens were prepared by uniaxial pressing at $200 \mathrm{MPa}$ of pressure in a steel cylindrical die $(2.5 \mathrm{~mm}$ thick, $10 \mathrm{~mm} \phi)$. The green density was approximately $2.9 \mathrm{~g}$ $\mathrm{cm}^{-3}$, i.e. $49 \%$ of theoretical density $\left(6.08 \mathrm{~g} \mathrm{~cm}^{-3}\right)$. Before MW sintering, the binder of the nanopowders was burnt out under air in an electric furnace by heating at $5{ }^{\circ} \mathrm{C} \min ^{-1}$ up to $600{ }^{\circ} \mathrm{C}$ and by soaking for $3 \mathrm{~h}$. The weight loss and shrinkage were about $0.5 \%$ and $20 \%$, respectively. This preliminary debinding stage is necessary, since we observed cracks development during microwave heating for other specimens. After, all samples were sintered by different methods at $1300{ }^{\circ} \mathrm{C}$ and $1400{ }^{\circ} \mathrm{C}$ of final temperature. 
Zirconia exhibit low dielectric losses at room temperature ( 0.04) and increases markedly to $\sim 1000$ around $1000{ }^{\circ} \mathrm{C}$. This combined with low thermal conductivity $\sim 2 \mathrm{~W}$ $\mathrm{m}^{-1} \mathrm{~K}^{-1}$ and high thermal expansion $\left(\alpha=10^{-6} \mathrm{~K}^{-1}\right)$ suggest that thermal stresses resulting from non uniform and/or fast heating may cause warpage/cracking. Therefore, SiC crucible with a high dielectric loss must be used as a susceptor in heating by microwave. Green samples were sintered in an experimental microwave oven with 800 $\mathrm{W}$ of power and $2.45 \mathrm{GHz}$ of frequency in microwave mono-mode rectangular cavity (Figure 1). This resonant cavity is coupled by an iris which dimensions are optimized for this application. The method to tune and detune the cavity consists of a sliding short circuit that can be moved electronically, depending on the reflected and consumed power and on the material temperature. The temperature was measured with an optical pyrometer (Optris $\mathrm{GmbH}$, Germany) through a circular hole located on the top of the cavity.

\section{(Figure 1)}

The microwave sintered samples were heated with a heating rate of $30{ }^{\circ} \mathrm{C} \min ^{-1}$ and a holding time of 10 minutes. Other non-conventional technique is pulsed electric currentassisted sintering, where the powder was placed into a graphite die with an inner diameter of $20 \mathrm{~mm}$ and cold uniaxially pressed at $30 \mathrm{MPa}$. Then, they were introduced in a pulsed electric-current pressure sintering HP D 25/1 (FCT Systeme GmbH, Germany) under low vacuum $\left(10^{-1} \mathrm{mbar}\right)$. The holding time was to $1 \mathrm{~min}$ at the maximum temperature under an applied pressure of $80 \mathrm{MPa}$ and a heating rate of 100 ${ }^{\circ} \mathrm{C} \min ^{-1}$. The conventional heating process was carried out in an electrical furnace (Thermolyne type 46100 ) with $5^{\circ} \mathrm{C} \min ^{-1}$ heating rate and $1 \mathrm{~h}$ of holding time. 
The density was measured by the Archimedes method (ISO-3369). In order to investigate sample microstructure, polished sections (Struers, model RotoPol-31) with diamond to $1 \mu \mathrm{m}$ roughness, were thermally etched between $30 \mathrm{~min}$ in an electrical furnace under air $100{ }^{\circ} \mathrm{C}$ below their maximum sintering temperature to reveal their microstructure. These sections have been observed using a field emission scanning electron microscope (FE-SEM, S4100 HITACHI). The grain size of the sintered samples was determined by multiplying the average linear intercept by 1.56 [22]. For each specimen, at least 15 lines were taken, and their average was reported.

\section{Results and Discussion}

Table 1 shows the sintering parameters, relative densities and average grain size of $3 \mathrm{Y}$-TZP powders densified using the sintering methodologies of CS, MW and PECS. It can be observed, a meaningful difference between the relative densities of the conventionally sintered samples and those prepared by MW and PECS.

\section{(Table 1)}

At $1300{ }^{\circ} \mathrm{C}$, the density of the MW sample was significantly higher than that of the CS and PECS samples. At this temperature if we compare the samples sintered by MW with 10 min of dwelling time and CS with $1 \mathrm{~h}$ of dwelling time, the MW sample has a density enhancement up to $7 \%$ (from $92.5 \%$ to $99.4 \%$ ) in a shorter time.

On increasing the temperature to $1400{ }^{\circ} \mathrm{C}$ a significant improvement in densification is observed in the CS samples. On the other hand, the MW method shows full dense samples compared to the pressed compacts sintered by PECS at equivalent 
temperatures. Therefore, maximum densification was provided by MW, wherein samples could be sintered to $>99.9 \%$ at a temperature of $1400{ }^{\circ} \mathrm{C}$ for 10 minutes. According to previous reports [16,19], microwave heating has been recognized as a promising method to improve the densification in the same ceramic systems.

During microwave heating energy is transferred to the material electromagnetically and not as a thermal heat flux enabling the material to be heated at rapid rates. The higher oxygen vacancies associated with $3 \mathrm{~mol} \%$ yttria-stabilized zirconia provides higher ionic conductance at elevated temperatures leading to high dielectric losses and enhanced absorption of microwaves. This mechanism could be one possible reason for the shorter sintering times in MW.

The rapid densification of samples by PECS is attributed to the enhanced densification rate due to mechanisms such as particle rearrangement and the breaking up of agglomerates aided by applied pressure and faster heating rates. By rearrangement of particles, the PECS process also impedes the pore size increasing which was generally observed in the first and intermediate stages of sintering. Further, applied electric field also promotes the diffusion of ions and vacancies which enhances the sintering rate.

But this method has a big problem with the sintering of zirconia materials. As can be observed in Figure 2a, the sample sintered by PECS at $1300{ }^{\circ} \mathrm{C}$ shows a full black colour. This is due to carbon diffusion within the zirconia sample by PECS processing, which is linked to the carbon rich atmosphere in which it is performed. As the sintering of the compact is taking place in a graphite die, the carbon diffuses into the sample from the die and this process is promoted by the applied pressure. Eliminating this contamination is possible (Figure $2 b$ ), but this implies high temperatures $\left(>800{ }^{\circ} \mathrm{C}\right.$ ) and a long time inside a furnace $(>2 \mathrm{~h})$, resulting in high economic costs. 


\section{(Figure 2)}

Figure 3 represents the FE-SEM microstructure of 3Y-TZP samples sintered by PECS, MW and CS at $1400{ }^{\circ} \mathrm{C}$. All the sintered specimens exhibited equiaxed grain microstructures and the average grain size varied over a wide range from $135 \mathrm{~nm}$ to 256 nm.

(Figure 3)

Nanocrystalline 3Y-TZP ceramics with average grain size of $225 \mathrm{~nm}$ and a complete elimination of residual porosity were obtained at $1400{ }^{\circ} \mathrm{C}$ for $10 \mathrm{~min}$ by $\mathrm{MW}$. The CS samples revealed a slight grain growth with an average grain size of $256 \mathrm{~nm}$, and the PECS of $245 \mathrm{~nm}$. These microstructures show similar values of grain size, but the MW micrograph (Figure 3b) shows a better homogeneous microstructure than the PECS and CS ones. Therefore, application of a heating microwave method has provided traces of improvement for grain growth suppression and densification compared to the other sintering techniques employed.

\section{Conclusions}

The microstructural evolution of the nanometric 3Y-TZP powder subjected to different sintering techniques (MW, PECS and CS), has been carried out in the current investigation. Comparison with conventional sintering shows that microwave sintering has a number of benefits in terms of microstructural design. Zirconia powders sintered by the microwave technique at the temperature of $1400{ }^{\circ} \mathrm{C}$ shows a full density of 
99.9\% at an average grain size of $225 \mathrm{~nm}$ with a more homogeneous microstructure compared to the specimen conventionally sintered at the same temperature.

\section{Acknowledgements}

This work has been carried out with programme to support research and development of the Polytechnic University of Valencia (U.P.V) under multidisciplinary projects PAID-05-09 and PAID-05-10. A. Borrell, acknowledges the Spanish Ministry of Science and Innovation for her FPI Ph.D. grant and the people from Institute Technological of Materials (ITM) of the U.P.V for helping us with the microwave experiments during a stay in 2010-2011. Felipe L. Peñaranda-Foix wants to thank the Generalitat Valenciana for the grant obtained in the frame of the Program BEST/2010, because some results of this paper have been possible with the help of.

\section{References}

[1] M.J. Mayo, Processing of nanocrystalline ceramics from ultrafine particles, Int. Mater. Rev. 41 (1996) 85-115.

[2] S. Deville, L. Gremillard, J. Chevalier, G. Fantozzi, A critical comparison of methods for the determination of the aging sensitivity in biomedical grade yttriastabilized zirconia, J. Biomed. Mater. Res. B. Appl. Biomater. 72 (2005) 239-245.

[3] U. Anselmi-Tamburini, J.E. Garay, Z.A. Munir, Fast low-temperature consolidation of bulk nanometric-ceramic materials, Scripta Mater. 54 (2006) 823-828.

[4] L. Gao, Z.J. Shen, H. Miyamoto, M. Nygren, Superfast densifcation of oxide/oxide ceramic composites, J. Am. Ceram. Soc. 82 (1999) 1061-1063. 
[5] T. Nishimura, M. Mitomo, H. Hirotsuru, M. Kawahara, Fabrication of silicon nitride nano-ceramics by spark plasma sintering, J. Mater. Sci. Lett. 14 (1995) 1046-1047.

[6] M. Yoshimura, T. Ohji, M. Sando, K. Niihara, Rapid rate sintering of nano grained $\mathrm{ZrO}_{2}$-based composites using pulse electric current sintering method, J. Mater. Sci. Lett. 17 (1998) 1389-1391.

[7] R. Chaim, Superfast densification of nanocrystalline oxide powders by spark plasma sintering, J. Mater. Sci. 41 (2006) 7862-7871.

[8] R. Chaim, Densification mechanisms in spark plasma sintering of nanocrystalline ceramics, Mater. Sci. Eng. A. 443 (2006) 25-32.

[9] A. Goldstein, N. Travitzky, A. Singurindy, M. Kravchik, Direct microwave sintering of yttria-stabilized zirconia at 2.45 GHz, J. Eur. Ceram. Soc. 19 (1999) 2067-2072.

[10] P. Both, N. Lequeux, Do microwaves increase the treatment sinterability of ceramic?, Sol. Sta. Ion. 101-103 (1997) 1229-1233.

[11] D.D. Upadhaya, A. Ghosh, K.R. Gurumurthy, R. Prasad, Microwave sintering of cubic zirconia, Ceram. Int. 27 (2001) 415-418.

[12] M. Mizuno, S. Obata, S. Takayama, S. Ito, N. Kato, T. Hiraia, M. Sato, Sintering of alumina by $2.45 \mathrm{GHz}$ microwave heating, J. Eur. Ceram. Soc. 24 (2004) 387-391.

[13] J. Raabe, E. Bobryk, V. Petrovsky, Fabrication of mullite-zirconia composites by microwave sintering of corundum/amorphous silica particles and sol-gel substrates, Ceram. Int. 27 (2001) 81-84.

[14] T. Ebadzadeh, M.H. Sarrafi, E. Salahi, Microwave-assisted synthesis and sintering of mullite, Ceram. Int. 35 (2009) 3175-3179.

[15] M.L. Sandoval, M.H. Talou, P.M. de Souto, R.H.G.A. Kiminami, M.A. Camerucci, Microwave sintering of cordierite precursor green bodies prepared by starch consolidation, Ceram. Int. 37 (2011) 1237-1243. 
[16] J. Wang, J. Binner, B. Vaidhyanathan, N. Joomun, J. Kilner, G. Dimitrakis, T.E. Cross, Evidence for the microwave effect during hybrid sintering, J. Am. Ceram. Soc. 89 (2006) 1977-1980.

[17] T. Ebadzadeh, M. Valefi, Microwave-assisted sintering of zircon, J. Alloys Comp. 448 (2008) 246-251.

[18] C. García-Gañan, J.J. Meléndez-Martínez, D. Gómez-García, A. DomínguezRodríguez, Microwave sintering of nanocrystalline Ytzp (3 Mol\%), J. Mater. Sci. 41 (2006) 5231-5234.

[19] J. Cheng, D. Agrawal, Y. Zhang, R. Roy, Microwave sintering of transparent alumina, Mater. Lett. 56 (2002) 587-592.

[20] S.A. Nightingale, D.P. Dunne, H.K. Worner, Sintering and grain growth of 3 mol\% yttria zirconia in a microwave field, J. Mater. Sci. 31 (1996) 5039-5043.

[21] S.A. Nightingale, H.K. Worner, D.P. Dunne, Microstructural development during the microwave sintering of yttria-zirconia ceramics, J. Am. Ceram. Soc. 80 (1997) 394400.

[22] Y. Wang, Z. Fu, Study of temperature field in spark plasma sintering, Mater. Sci. Eng. B. 90 (2002) 34-37. 


\section{Figure Captions:}

Figure 1. Microwave system setup.

Figure 2. (a) 3Y-TZP sample sintered by PECS and (b) 3Y-TZP sample sintered by PECS after heating treatment.

Figure 3. FE-SEM micrographs of near full dense specimens sintered by PECS at $1400^{\circ} \mathrm{C} / 1 \mathrm{~min}(\mathrm{a}), \mathrm{MW}$ at $1400^{\circ} \mathrm{C} / 10 \mathrm{~min}(\mathrm{~b})$, and $\mathrm{CS}$ at $1400^{\circ} \mathrm{C} / 60 \mathrm{~min}(\mathrm{c})$. 


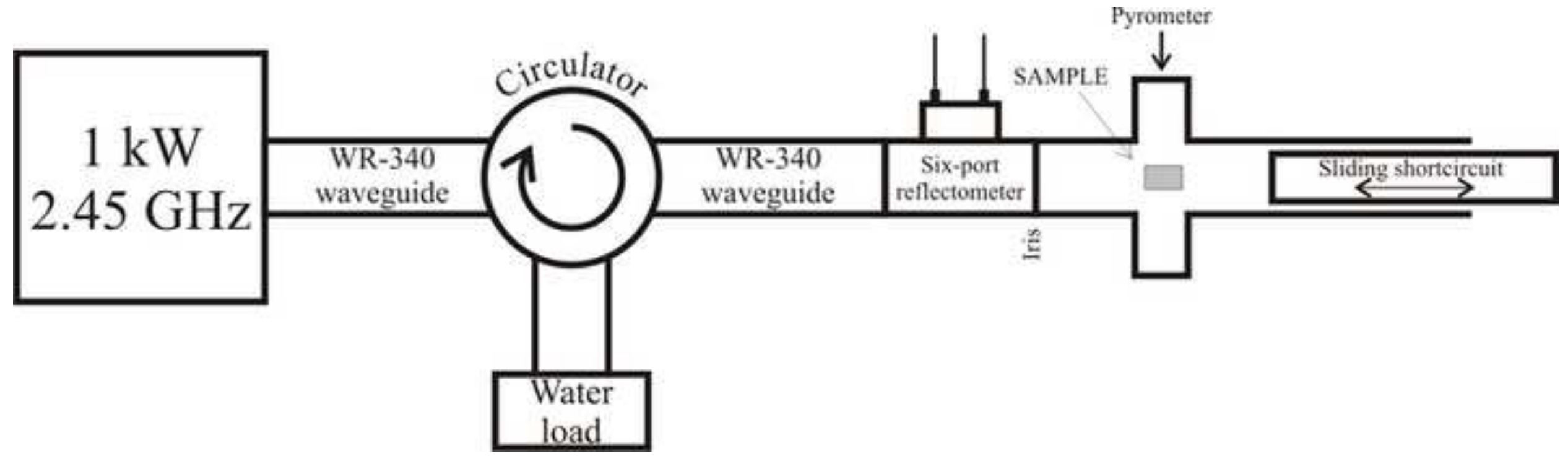


Click here to download high resolution image

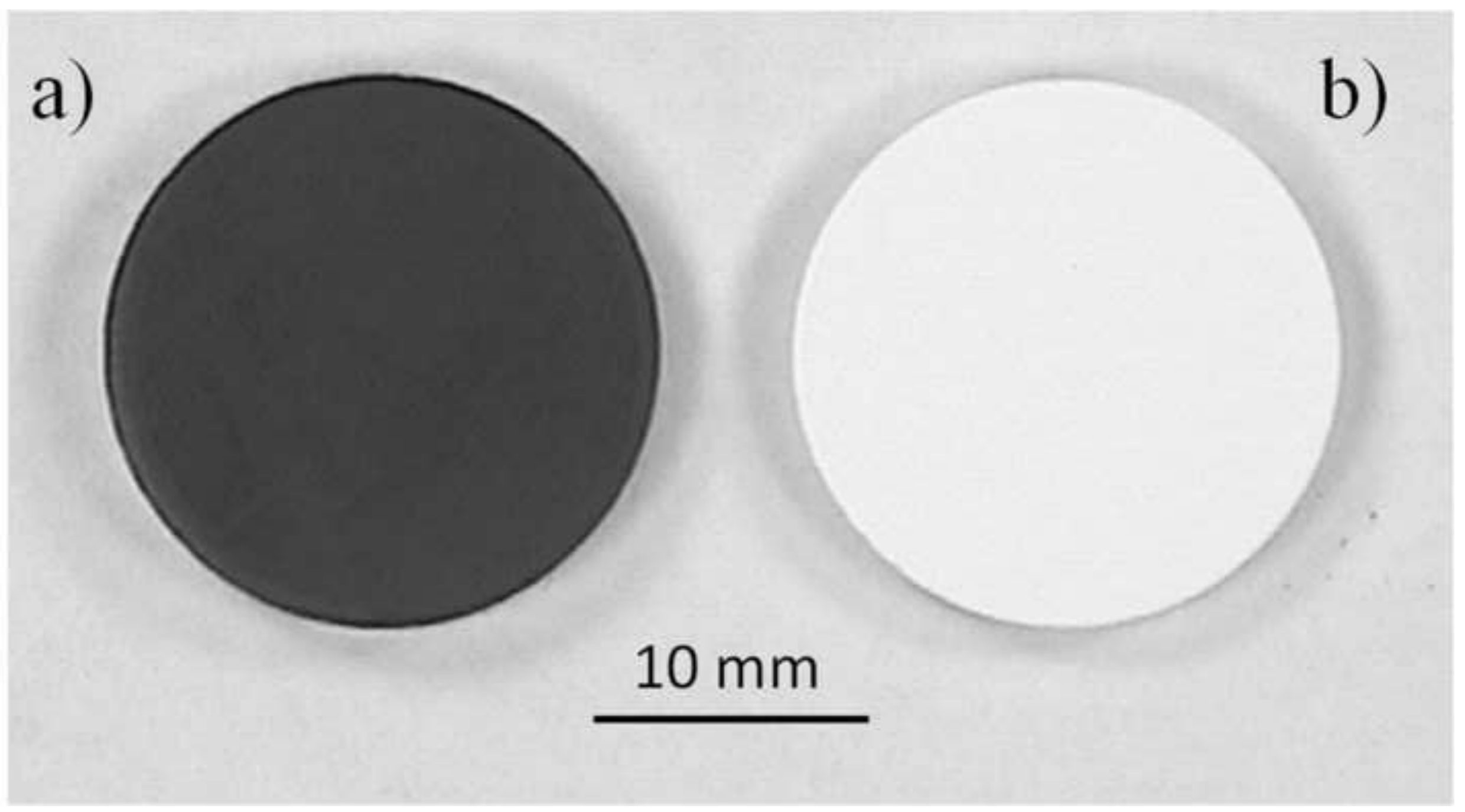


Figure 3

Click here to download high resolution image
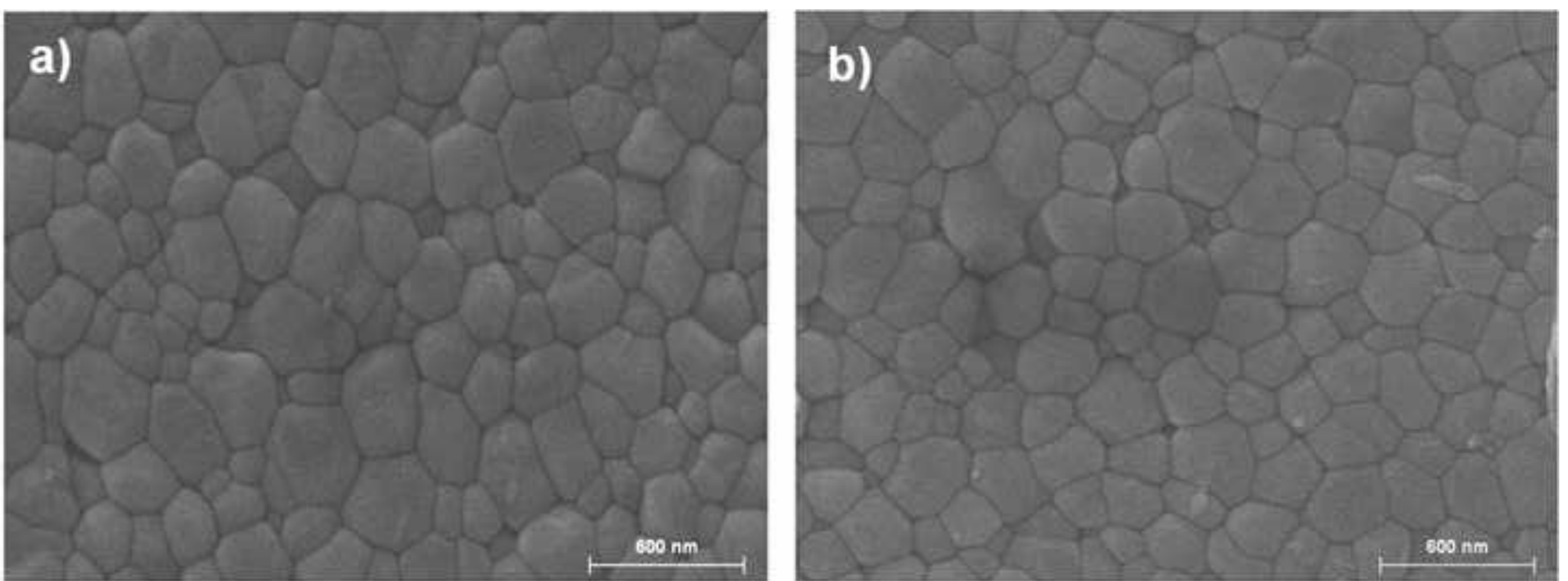

\section{c)}




\begin{tabular}{|c|c|c|c|c|}
\hline $\begin{array}{l}\text { Sintering } \\
\text { technique }\end{array}$ & $\begin{array}{c}\text { Final } \\
\text { temperature }\left({ }^{\circ} \mathrm{C}\right)\end{array}$ & $\begin{array}{c}\text { Dwell time } \\
\text { (min) }\end{array}$ & $\begin{array}{l}\text { Relative density } \\
\text { (\% t.d })\end{array}$ & $\begin{array}{l}\text { Average grain } \\
\text { size }(\mathrm{nm})\end{array}$ \\
\hline CS & $\begin{array}{l}1300 \\
1400\end{array}$ & $\begin{array}{l}60 \\
60\end{array}$ & $\begin{array}{l}92.5 \pm 0.5 \\
98.3 \pm 0.5\end{array}$ & $\begin{array}{l}165 \pm 5 \\
256 \pm 3\end{array}$ \\
\hline MW & $\begin{array}{l}1300 \\
1400\end{array}$ & $\begin{array}{l}10 \\
10\end{array}$ & $\begin{array}{l}99.4 \pm 0.5 \\
99.9 \pm 0.5\end{array}$ & $\begin{array}{l}188 \pm 6 \\
225 \pm 4\end{array}$ \\
\hline PECS & $\begin{array}{l}1300 \\
1400\end{array}$ & $\begin{array}{l}1 \\
1\end{array}$ & $\begin{array}{l}98.7 \pm 0.5 \\
99.0 \pm 0.5\end{array}$ & $\begin{array}{l}135 \pm 6 \\
245 \pm 5\end{array}$ \\
\hline
\end{tabular}

Table 1. Sintering parameters, sintered densities and average grain size of the 3Y-TZP materials. 